\title{
MALIGNANT SOMATOSTATINOMA PRESENTING WITH DIABETIC KETOACIDOSIS
}

\author{
J. A. JACKSON, B. U. RAJU, J. D. FACHNIE, \\ R. C. MELLINGER, N. JANAKIRAMAN, R. V. LLOYD \\ AND A. I. VINIK
}

The Departments of Internal Medicine and Pathology, Henry Ford Hospital, Detroit, MI 48201, USA, and the Departments of Pathology and Internal Medicine and Surgery, University of Michigan, Ann Arbor, MI 48109, USA

(Received 8 September 1986; returned for revision 21 October 1986; finally revised 14 November 1986; accepted 9 December 1986)

\section{SUMMARY}

High circulating levels of somatostatin (SRIF) were detected in a patient with a metastatic tumour after development of diabetic ketoacidosis (DKA). Fasting insulin and C-peptide levels were markedly suppressed, but plasma glucagon was not suppressed below normal. Progressive cachexia ensued; at autopsy a poorly differentiated non-small cell neuroendocrine carcinoma metastatic to liver was found. Small gallstones were noted. Electron microscopy of tumour tissue showed neurosecretory granules and tonofilament bundles. Immunohistochemical staining of tumour cells was diffusely positive for carcinoembryonic antigen, bombesin-like immunoreactivity, and calcitonin with focal immunoreactivity for SRIF, serotonin, neuron-specific enolase, chromogranin, and epithelial membrane antigen. Column chromatography of plasma and tumour extract revealed five or more peaks of material with SRIF-like immunoreactivity (SRIF-LI): predominantly SRIF-28 and intermediates in tumour extract, and SRIF-14 and an intermediate between SRIF-28 and SRIF-14 in plasma. DKA in this case of somatostatinoma syndrome may reflect differential effects of tumour production of larger molecular weight SRIF forms on insulin and glucagon secretion.

The somatostatinoma syndrome as has been described (Larsson et al., 1977; Ganda et al., 1977; Galmiche et al., 1978; Krejs et al., 1979; Pipeleers et al., 1979; Gerlock Jr et al., 1979; Ghose \& Gupta, 1981; Axelrod et al., 1981; Schusdziarra et al., 1983; Kelly, 1983; Nakanome et al., 1984) includes steatorrhoea, hypochlorhydria, cholelithiasis, and generally mild non-ketotic hyperglycaemia. The absence of ketoacidosis in somatostatinoma patients has been regarded as consistent with theoretical considerations (Unger, 1977; Krejs et al., 1979) and experimental studies (Gerich et al., 1975a; Keller et al., 1977)

Correspondence: Jeffrey A. Jackson, M.D., Department of Internal Medicine, Division of Endocrinology, Scott and White Clinic, 2401 South 31st Street, Temple, Texas 76508, USA. 
of the effects of simultaneous inhibition of insulin and glucagon secretion by somatostatin.

This report describes the clinical, biochemical, and morphologic features of a patient with a malignant somatostatinoma in whom the diagnosis was recognized after presentation with spontaneous overt diabetic ketoacidosis.

\section{CASE REPORT}

A 74-year-old retired male carpenter with a 120-pack-year smoking history developed foul-smelling greasy stools, early satiety, and $7 \mathrm{~kg}$ of weight loss over a 3 -month period. In June 1984 a left apical-posterior lung mass was found on chest X-ray. At this time hemoglobin was $13.4 \mathrm{~g} / 100 \mathrm{ml}$ with mildly elevated liver function tests and a random sugar of $5.4 \mathrm{mmol} / \mathrm{l}$. Staging chest and adrenal computed tomography showed a 2 $\mathrm{cm} \times 2.5 \mathrm{~cm}$ left apical pulmonary mass and multiple large liver masses with a normal pancreas. Serum carcinoembryonic antigen (CEA) was $7.5 \mu \mathrm{g} / 1$ (normal $0-5 \mu \mathrm{g} / 1$ ) and serum alpha f $_{1}$-fetoprotein was $9.9 \mu \mathrm{g} / 1$ (normal $<11 \mu \mathrm{g} / 1$ ). Tissue obtained by open liver biopsy was diagnosed as poorly differentiated adenocarcinoma. Transthoracic needle biopsy of the left apical mass was unsuccessful. Chemotherapy with cisplatin and vinblastine sulphate was initiated in August 1984 but failed to produce evidence of tumour response after two courses of therapy.

The patient had continued malabsorptive diarrhoea and weight loss between June and September 1984 with gradually increasing blood glucose levels of $6 \cdot 8-16 \cdot 2 \mathrm{mmol} / \mathrm{l}$. He received 5-fluorouracil, vincristine sulphate, and mitomycin-C in late September 1984. Eight days later he was admitted with polyuria, polydipsia, lethargy, Kussmaul respiration, and a left-sided pneumonic infiltrate. Mild hyperpigmentation was noted. Blood glucose was $61 \cdot 1 \mathrm{mmol} / 1$ and arterial $\mathrm{pH}$ was $7 \cdot 19$ with a plasma bicarbonate of 5 $\mathrm{mmol} / 1$ (normal $2432 \mathrm{mmol} / \mathrm{l}$ ). Serum ketones (Acetest-Ames Co, Elkhart, Indiana, USA) were positive at a dilution of $1: 16(>16 \mathrm{mmol} / 1$ acetoacetate $)$ and blood lactate was $7.7 \mathrm{mmol} / 1$ (normal 0-2 mmol/1). Serum osmolality was $380 \mathrm{mmol} / \mathrm{kg}$ (normal $280-290$ $\mathrm{mmol} / \mathrm{kg}$ ). The patient responded well to parenteral fluids, insulin, and antibiotics. Endocrinologic consultation was obtained and further testing was performed (Table 1). Evidence of steatorrhoea and malabsorption was found with a $24-\mathrm{h}$ faecal fat content of $13.3 \mathrm{~g}$ and an abnormal $\mathrm{D}$-xylose test $(3.7 \mathrm{~g} / 5 \mathrm{~h}$ urine (normal $>5 \mathrm{~g} / 5 \mathrm{~h}$ urine)). He became hypoglycaemic on 20 units of insulin per day and insulin was discontinued within 3 weeks with subsequent blood glucose levels $<13.9 \mathrm{mmol} / \mathrm{l}$. Steatorrhoea cleared with use of pancreatic enzymes alone and the patient was discharged.

Out-patient follow-up in December 1984 disclosed further weight loss with maintenance of normal random blood sugars. Hormonal studies at this time are shown in Table 1. Chest X-ray showed enlargement of the apical lung mass. The patient refused further chemotherapy until March 1985 when he was admitted for preparative parenteral hyperalimentation before anticipated streptozotocin therapy. Additional biochemical and hormonal studies were obtained (Table 1). Insulin was added to the hyperalimentation solutions as moderate non-ketotic hyperglycaemia developed. The patient developed pneumonia and sepsis and expired in late March 1985.

At postmortem examination a tumour mass measuring $1.5 \mathrm{~cm} \times 2.6 \mathrm{~cm}$ was present in the left upper lobe apex of the lung with bilateral multiple small subpleural metastatic nodules. A large metastatic right hepatic lobe mass measuring $10 \mathrm{~cm} \times 15 \mathrm{~cm}$ (liver weight 
Table 1. Biochemical and hormonal data*

\begin{tabular}{|c|c|c|c|c|c|}
\hline \multirow[b]{2}{*}{ Assay } & \multirow[b]{2}{*}{ Normal } & \multicolumn{4}{|c|}{ Date } \\
\hline & & Oct 84 & Dec 84 & Feb 85 & Mar 85 \\
\hline Blood glucose $(\mathrm{mmol} / \mathrm{l})$ & $3 \cdot 3-5 \cdot 6 \uparrow$ & $7 \cdot 7 \uparrow$ & $7 \cdot 3+\dagger$ & $6 \cdot 4 \dagger \dagger$ & - \\
\hline Somatostatin-like immunoreactivity (ng/l) & $20-40$ & 5070 & 2930 & 8300 & 4900 \\
\hline Carcinoembryonic antigen $(\mu \mathrm{g} / \mathrm{l})$ & $0-5$ & - & - & - & $44 \cdot 7$ \\
\hline $\mathrm{GH}(\mu \mathrm{g} / 1)$ & $0-5$ & $<0.7$ & - & - & - \\
\hline Cortisol (mmol/l) & $220-770 \dagger$ & $260 \dagger$ & - & - & - \\
\hline $\mathrm{ACTH}(\mathrm{pmol} / \mathrm{l})$ & $<29$ & $<2$ & - & - & - \\
\hline Gastrin (ng/l) & $<150$ & $18 \cdot 0$ & - & - & - \\
\hline Pancreatic polypeptide (ng/1) & $<1000$ & $12 \cdot 0$ & - & - & - \\
\hline Vasoactive intestinal polypeptide (ng/l) & $<50$ & $<10$ & 一 & - & - \\
\hline Substance P (ng/l) & $<25$ & $<10$ & - & - & - \\
\hline Calcitonin $(\mu \mathrm{g} / 1)$ & $<0.35$ & - & $<0 \cdot 1$ & - & - \\
\hline Immunoreactive insulin (pmol/l) & $36-179 \div$ & $14 \cdot 0 \dagger$ & - & - & - \\
\hline Immunoreactive glucagon (ng/l) & $50-200 \dagger$ & $98.0+$ & - & - & - \\
\hline C-peptide $(\mu \mathrm{g} / \mathrm{l})$ & $1 \cdot 5-3 \cdot 2 \dagger$ & $<0.25 \dagger$ & - & - & - \\
\hline Bombesin-like immunoreactivity (ng/l) & $<250$ & - & - & - & 220 \\
\hline
\end{tabular}

\footnotetext{
* Hormone concentrations were measured by radioimmunoassay as described in text.

$\uparrow$ Fasting.

†† Random.
}

$3790 \mathrm{~g})$ and a right adrenal metastasis $(1.0 \mathrm{~cm} \times 1.3 \mathrm{~cm})$ were also found. The pancreas was free of tumour. Numerous small gallstones were noted. Multiple bilateral pulmonary thromboemboli were identified.

\section{MATERIALS AND METHODS}

\section{Tumour morphology and immunohistochemistry}

Tumour from lung and liver was fixed in buffered $10 \%$ formalin before embedding in paraffin and 6- $\mu \mathrm{m}$ thick sections were utilized for light microscopy and immunohistochemical examination. Sections were stained with haematoxylin and eosin (H \& E), periodic acid Schiff (PAS) with and without prior diastase digestion, alcian blue ( $\mathrm{pH} 2.5$ ), Cherukian-Schenk's argyrophil, and Fontana-Masson argentaffin stains. Immunoperoxidase staining was performed using the avidin-biotin complex method (Hsu et al., 1981) adapted for SRIF, vasoactive intestinal polypeptide (VIP), immunoreactive insulin (IRI), immunoreactive glucagon (IRG), pancreatic polypeptide (PP), gastrin, chromogranin, neuron-specific enolase (NSE), and ACTH (Lloyd et al., 1984). Details of the other specific antisera used for immunostaining are shown in Table 2.

For ultrastructural studies, tumour tissue was fixed in cold cacodylate buffered $3 \%$ glutaraldehyde, post-fixed in osmic acid, dehydrated and embedded in araldite. Ultrathin sections were prepared in a routine manner and examined with a Zeiss model 109 electron microscope. 
Table 2. Details of other immunohistochemical stains

\begin{tabular}{|c|c|c|}
\hline Specific antiserum/antibody* & Dilution & Source \\
\hline Carcinoembryonic antigen & $1: 500$ & Dako Corp (Santa Barbara, CA) \\
\hline Calcitonin & $1: 5000$ & Dako Corp (Santa Barbara, CA) \\
\hline $\mathrm{hCG}$ & $1: 800$ & Dako Corp (Santa Barbara, CA) \\
\hline Bombesin-like immunoreactivity & $1: 1000$ & Dr L. Frohman (Cincinnati, OH) \\
\hline Serotonin & $1: 7500$ & Immuno Nuclear Corp (Stillwater, MN) \\
\hline Beta-endorphin & $1: 100$ & Immuno Nuclear Corp (Stillwater, MN) \\
\hline Methionine-enkephalin & $\mathrm{I}: 100$ & Immuno Nuclear Corp (Stillwater, MN) \\
\hline Epithelial membrane antigen & $1: 500$ & Dako Corp (Santa Barbara, CA) \\
\hline Keratin & $1: 1000$ & Enzo Biochem (New York, NY) \\
\hline
\end{tabular}

*Anti-keratin was a mouse monoclonal antibody. All other antisera were polyclonal.

\section{Assay procedures}

Blood samples were collected in chilled tubes containing either heparin and Trasylol 500 $1000 \mathrm{kIU} / \mathrm{ml}$ whole blood (aprotinin-Mobay Chemical Corp, FBA Pharmaceuticals, New York, NY, USA); (SRIF-like immunoreactivity (SRIF-LI)), EDTA and Trasylol (VIP, IRG, and bombesin-like immunoreactivity (bombesin-LI)), heparin (PP), EDTA (GH, cortisol, ACTH and substance P) or no additives (CEA, gastrin, calcitonin (CT), IRI and C-peptide) and immediately centrifuged at $4^{\circ} \mathrm{C}$. Serum and plasma were stored at $-20^{\circ} \mathrm{C}$ until the time of assay. SRIF-LI was measured on unextracted plasma samples (Vinik et al., 1981a). CEA (Abbott Laboratories, Diagnostics Division, North Chicago, Illinois, USA), GH (Cambridge Medical Diagnostics, Inc., Billerica, Massachusetts, USA), cortisol (Amersham Corp, Arlington Heights, Illinois, USA), ACTH (Nichols Institute Reference Laboratories, San Juan Capistrano, California, USA), gastrin (Kothary et al., 1983), PP (Sive et al., 1980), VIP (Immuno Nuclear Corp, Stillwater, Minnesota, USA), substance P (Strodel et al, , 1984), CT (Tashjian Jr, 1969), IRI (Starr \& Rubenstein, 1974), IRG (using the Unger 30K antiserum-Smith Kline Bio-Science Laboratories, Van Nuys, California, USA), C-peptide (Starr \& Rubenstein, 1974), and bombesin-LI (Vinik et al., 1984) were measured by specific radioimmunoassays (RIAs). Blood glucose was measured by an automated analyser using glucose oxidase.

\section{Chromatographic studies}

Tumour from the hepatic metastasis $(0.85 \mathrm{~g})$ was extracted in $1.0 \mathrm{M}$ acetic acid. The extract, containing $535 \mathrm{ng}$ of SRIF-LI per g wet weight, was applied to a Sephadex G-50 superfine column $(100 \mathrm{~cm} \times 1.0 \mathrm{~cm})$ and eluted at $10 \mathrm{ml} / \mathrm{h}$ with $1.0 \mathrm{M}$ acetic acid. Column eluates were lyophilized and reconstituted in the assay buffer for RIA of SRIF-LI content using an antiserum that reacts with the mid- to carboxy-terminal portion of SRIF-14 and crossreacts on an equimolar basis with SRIF-25 and SRIF-28 (Vinik et al., 1981a, 1981 b). Plasma samples $(100 \mu \mathrm{l})$ from March 1985 , containing $4900 \mathrm{pg} / \mathrm{ml}$ of SRIF-LI, were applied directly to the column without prior extraction. Eluates were treated as for tumour extract. Recovery of SRIF-LI from tumour and plasma were $100 \%$ and $107 \%$, respectively. 

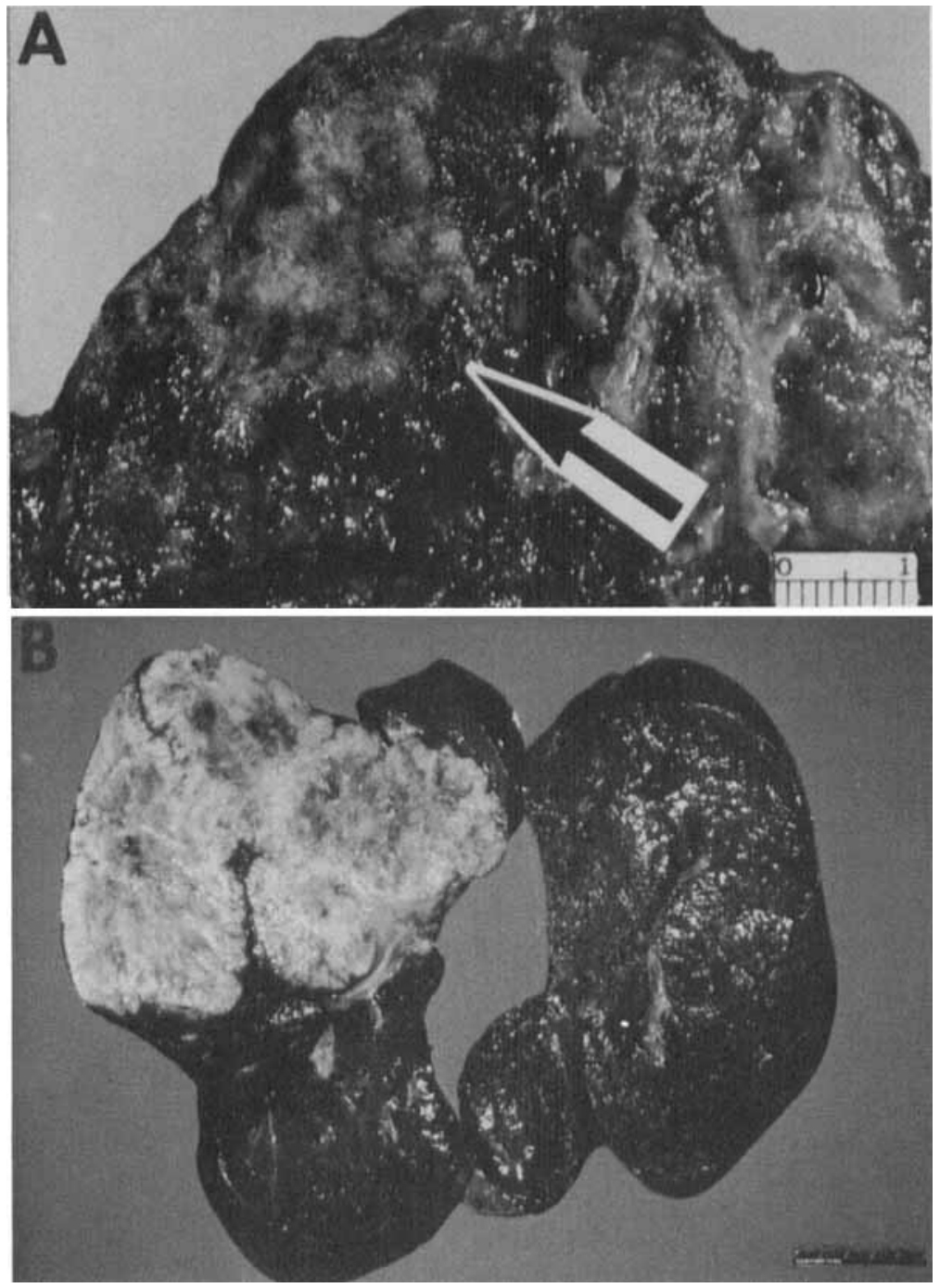

Fig. 1. Gross appearance of subpleural primary tumour (arrow) in the lung (A) and metastatic tumour mass in the liver (B).

\section{RESULTS}

\section{Tumour morphology}

Figure 1 shows the gross appearance of the tumour in the lung and liver. Light microscopy revealed nests and broad interanastomosing cords of medium to large size slightly pleomorphic cells with hyperchromatic irregular vesicular nuclei comprising the poorly differentiated carcinoma of the lung (Fig. 2A) and intrapulmonary, hepatic, and adrenal metastases. While specific differentiation was not readily apparent on the $\mathrm{H} \& \mathrm{E}$ stained sections, mucin stains identified multiple minute PAS-diastase positive and alcian blue 

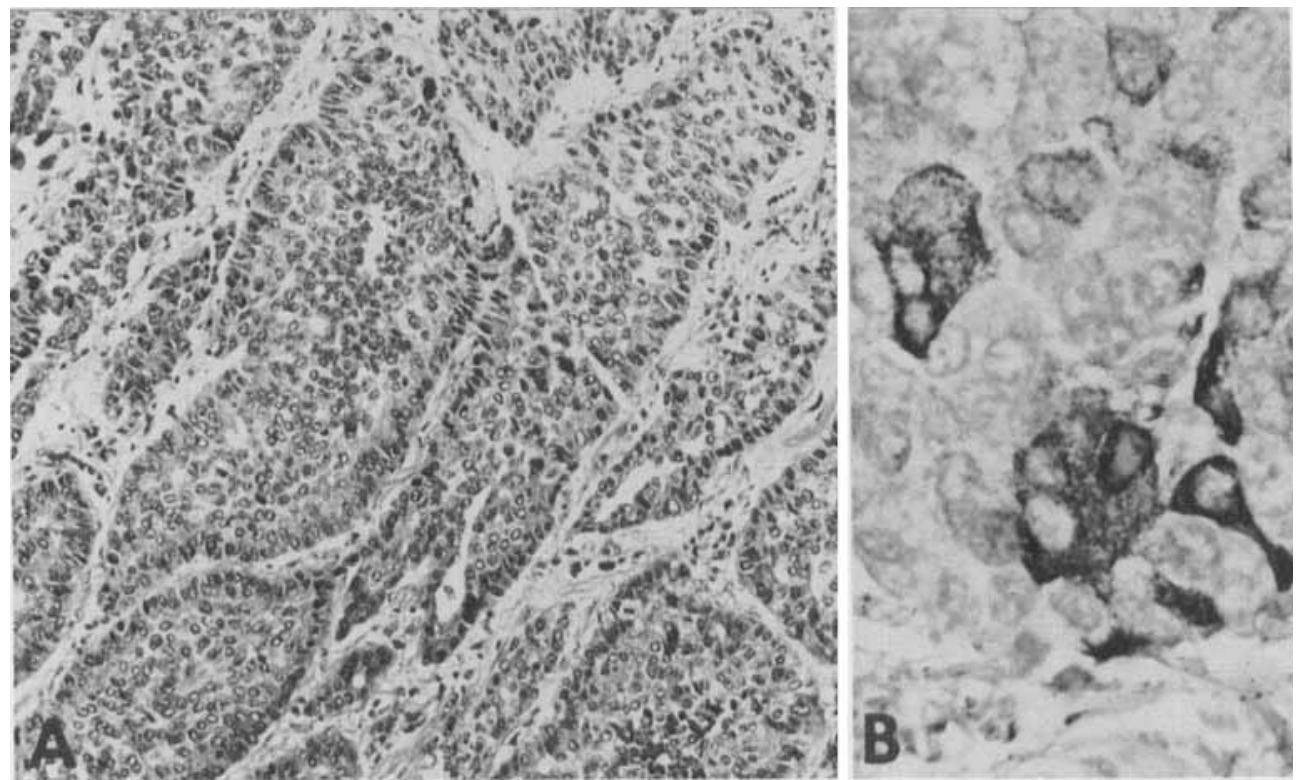

Fig. 2. (A) Section of the poorly differentiated carcinoma from the lung showing nests of tumour cells (hematoxylin and eosin stain $\times 80$ ). (B) Argyrophilic cytoplasmic granules in isolated clusters of cells within the tumour (Cherukian-Schenk's stain $\times 800$ ).

positive globules and ring-like areas consistent with intracellular mucin. A few isolated clusters of cells had argyrophilic granules (Fig. 2B) and none had argentaffin properties.

Ultrastructurally the partially autolysed tumour cells had adequate preservation to reveal the presence of well-formed desmosomes, bundles of tonofilaments in several cells, and clusters of $100 \mathrm{~nm}$ to $130 \mathrm{~nm}$ round dense-core neurosecretory granules in a basal location in some cells and randomly distributed in the others. The dense-core granules in different cells had little or no variation in size and shape. Tonofilaments and granules often coexisted in the same cell. Rare intracytoplasmic lumens with microvilli were present. Representative electron photomicrographs are shown in Fig. 3.

\section{Immunohistochemistry}

Diffuse immunoperoxidase staining for CEA (Fig. 4A) and bombesin-LI was demonstrated in more than $90 \%$ of the tumour cells from the primary (lung) and metastatic (liver) sites with $30-40 \%$ of tumour cells staining for CT. Approximately $10 \%$ of the tumour cells were focally positive for chromogranin and NSE, and 5-10\% were focally immunoreactive for SRIF (Fig. 4B), serotonin and epithelial membrane antigen (EMA). Immunohistochemical stains for glucagon, insulin, gastrin, PP, ACTH, hCG, betaendorphin, methionine-enkephalin and keratin were negative.

\section{Chromatographic studies}

Figure 5 shows the chromatographic profile of SRIF-LI in plasma and the liver tumour extract. Five or more peaks of immunoreactive material were found in both plasma and 


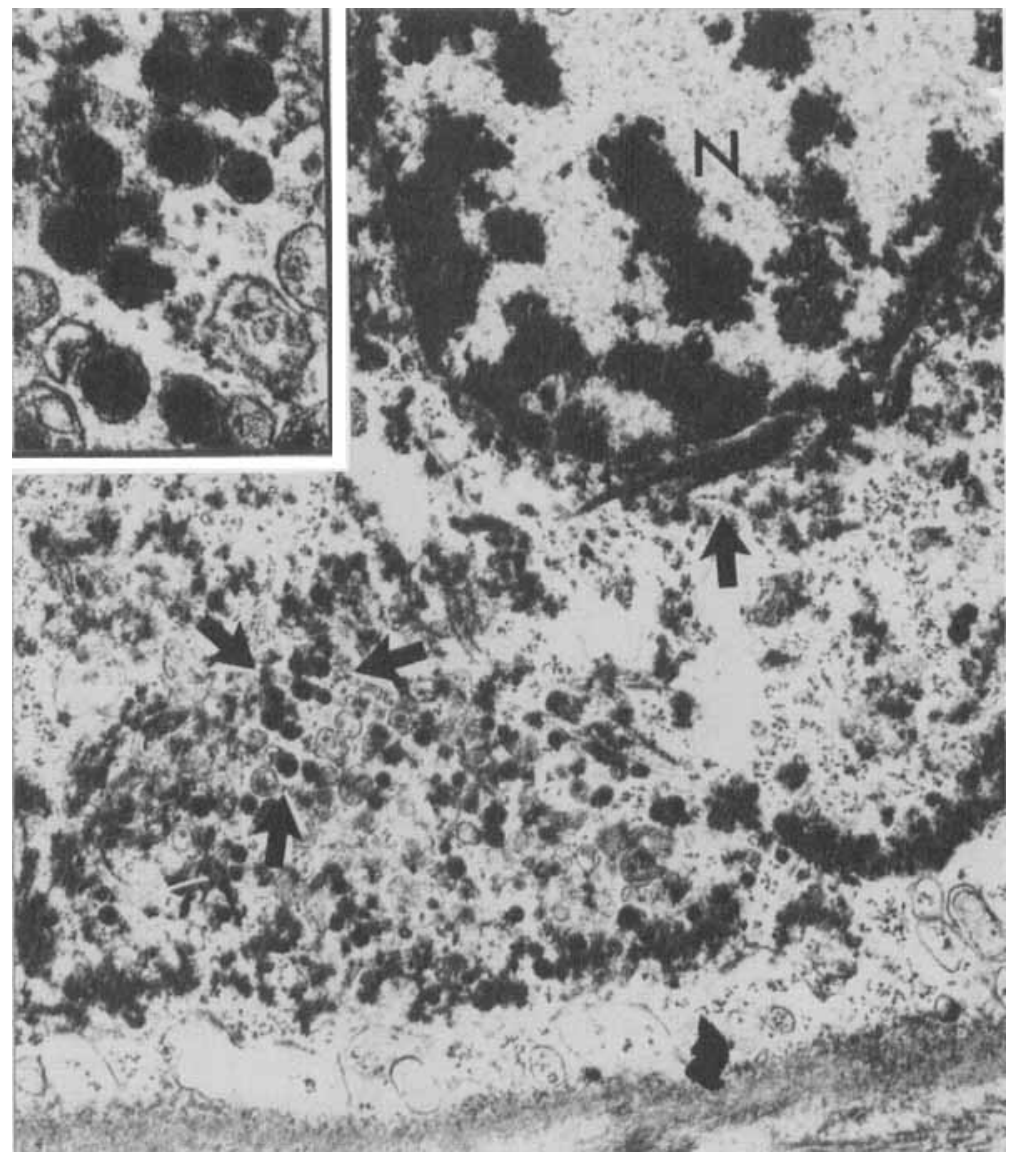

Fig. 3. Electron photomicrograph $(\times 13500)$ of tumour showing multiple dense-core granules in the basal location of cells (short arrows) and perinuclear tonofilaments (long arrows). Insert $(\times 42300)$ shows granule details: uniform dense-core with limiting membrane separated by a uniform lucent space $(\mathrm{N}$, nucleus).

tumour. The major forms of SRIF-LI in the tumour co-eluted with the SRIF-28 and SRIF-25 standard reference preparations with two forms intermediate in size between SRIF-28 and SRIF-14 and a peak corresponding with SRIF-14 itself. In plasma the dominant molecular forms were SRIF-14 and a species intermediate in size between SRIF-14 and SRIF-28, in addition to peaks corresponding to SRIF-28 and a large ( $>5 \mathrm{~K})$ molecular weight form.

\section{DISCUSSION}

The somatostatinoma syndrome in our patient consisted of steatorrhoea, weight loss, mild anaemia, gallstones, a malignant tumour metastatic to the liver, and progressive hyperglycaemia culminating in overt DKA. This case presents several unique aspects including the occurrence of spontaneous DKA with subsequent demonstration of greater 

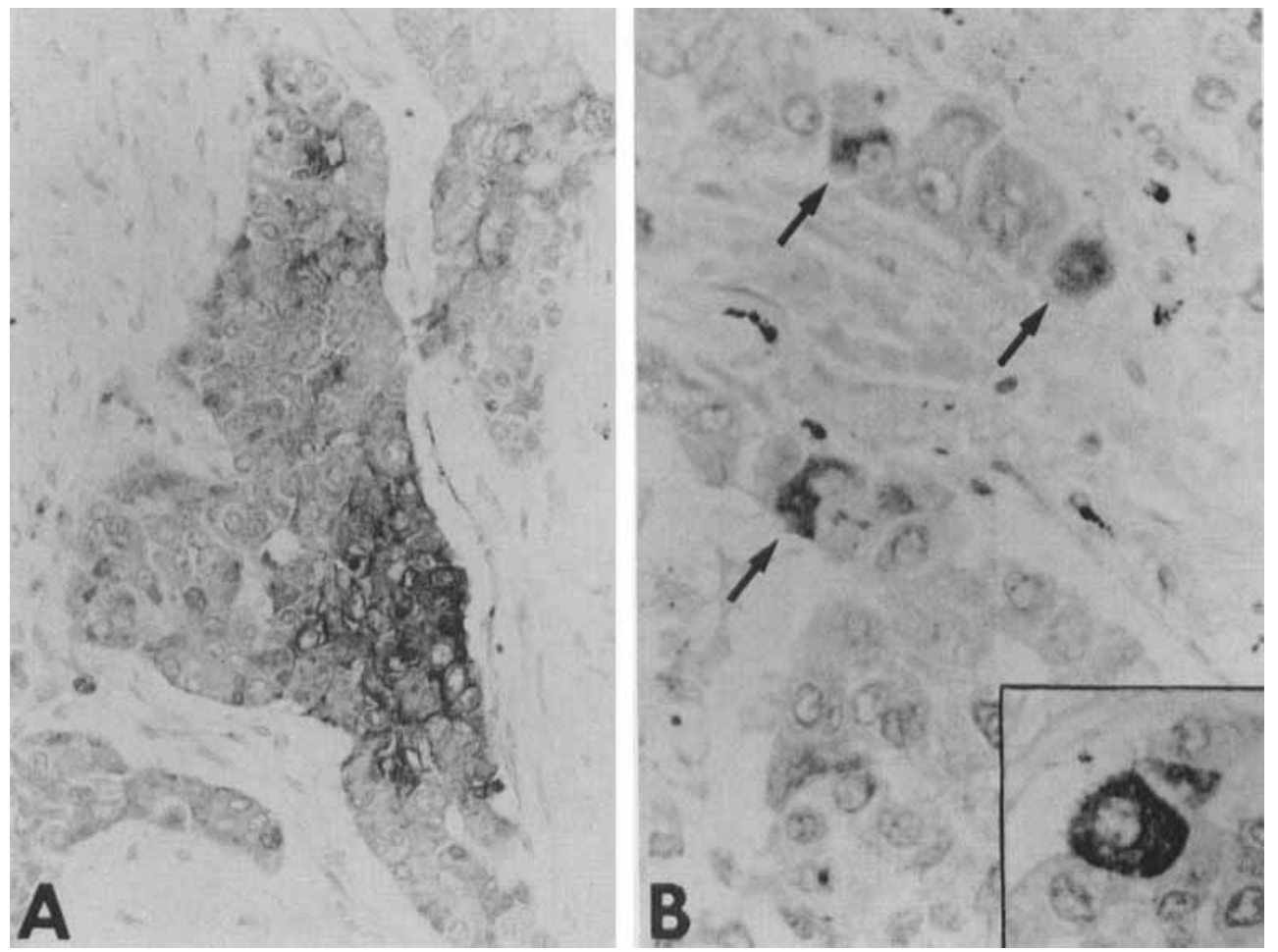

Fig. 4. (A) Immunoperoxidase staining for carcinoembryonic antigen showing diffuse tumour cell immunoreactivity (immunoperoxidase $\times 216$ ). (B) Immunoperoxidase staining for somatostatin showing a few tumour cells with positive reaction (arrows). Inset shows a single cell with strong positive cytoplasmic staining for somatostatin (immunoperoxidase $\times 432$ ).

suppression of insulin than glucagon. The absence of ketosis in most of the reported cases of the somatostatinoma syndrome may relate to the species of SRIF secreted by the individual tumours. One previous extrapancreatic source of SRIF (small cell carcinoma of the lung) as a cause of the characteristic syndrome has been reported (Ghose \& Gupta, 1981). The tumour in our case appears to have arisen as a primary in the lung, although we cannot, with absolute certainty, exclude the possibility of a small undetected primary elsewhere.

Spontaneous development of ketonuria, without ketonaemia, has been reported in one patient with a somatostatinoma (Axelrod et al., 1981). Upon withdrawal of insulin, this patient exhibited elevation of total blood ketone levels (peak $5.05 \mathrm{mmol} / \mathrm{l}$ ) without overt ketoacidosis. Basal IRI and IRG levels were low (43 pmol/1 and $<50 \mathrm{ng} / \mathrm{l}$, respectively) with predominant inhibition of IRG and only at high endogenous levels of SRIF-LI after treatment with streptozotocin was IRI inhibited. Our patient differed in that plasma IRG was not suppressed to below the normal range despite marked suppression of serum IRI and C-peptide, as well as plasma GH. This circulating concentration of glucagon was apparently sufficient to facilitate ketogenesis. The occurrence of DKA following chemotherapy may have been coincidental; at that time, factors known to precipitate ketogenesis such as infection and volume depletion with resultant impairment of insulin 


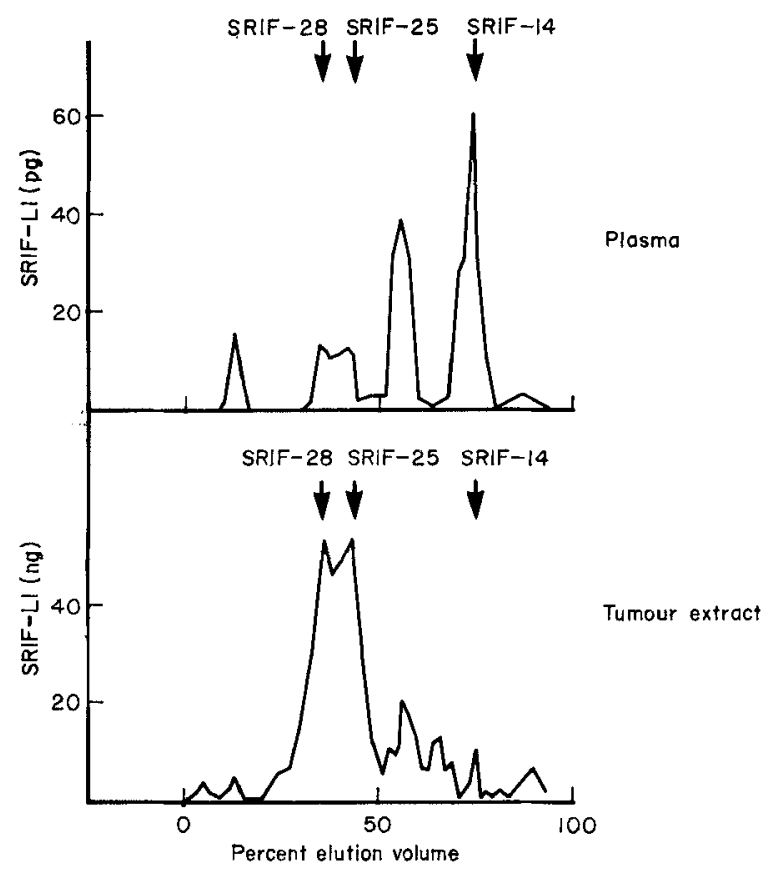

Fig. 5. Chromatographic profile of somatostatin-like immunoreactivity (SRIF-LI) in plasma (upper panel) and tumour extract (lower panel). The arrows indicate the elution position of synthetic standard reference preparations (SRIF-28, SRIF-25, and SRIF-14). The percent elution volume refers to that between blue dextran $(0 \%)$ and ${ }^{125} \mathrm{I}-\mathrm{Na}(100 \%)$. Fraction volume was $1.0 \mathrm{ml}$. See text for details of chromatography.

secretion and resistance to insulin action may have contributed significantly to the clinical picture in our patient. Nonetheless, the absence of previous description of overt ketoacidosis in the somatostatinoma syndrome suggests that the hormonal milieu in our case was in some way conducive to ketone production. Tumour lysis-induced SRIF release has been previously suggested as a possible precipitating factor for ketogenesis (Axelrod et al., 1981), but higher SRIF-LI levels were encountered 4 months later in our patient's course without recurrence of DKA.

Numerous studies have reported the presence of larger molecular weight forms of SRIF in patients with somatostatinomas (Larsson et al., 1977; Krejs et al., 1979; Pipeleers et al., 1979; Axelrod et al., 1981; Conlon et al., 1981; Penman et al., 1980). More recently SRIF28-LI has been detected in tumour extracts (Ito et al., 1982; Patel et al., 1983) and plasma (Patel et al., 1983) of somatostatinoma patients. On a molar basis, SRIF-28 is more potent than SRIF-14 in inhibiting GH, insulin, and pancreatic exocrine secretion (Susini et al., 1980; Brazeau et al., 1981; Mandarino et al., 1981). SRIF-28 is also relatively more diabetogenic than SRIF-14 when given exogenously (Tannenbaum et al., 1982). In contrast, SRIF-14 appears to be a more potent inhibitor of glucagon than of insulin release (Gerich et al., 1975b). These diverse physiologic effects of SRIF-14 and SRIF-28 may be subserved by two different types of SRIF receptors (Tran et al., 1985). Thus, the production of a relative excess of SRIF-28 would be expected to be conducive to the development of ketogenesis and fat malabsorption. 
The hormonal pattern in this patient, with greater suppression of IRI than of IRG levels, appears to be consistent with a SRIF-28-like effect. The chromatographic results showed predominance of SRIF-28 in tumour extract, although the major circulating forms late in our patient's course were SRIF-14 and intermediate in size between SRIF-14 and SRIF-28. The appearance of different chromatographic forms in plasma and tumour may be related to post-transcriptional processing or alterations in release of molecular forms of SRIF by the tumour. Alternatively, at the time the patient became ketoacidotic, the tumour could have secreted predominantly SRIF-28 which it clearly synthesized.

Our chromatographic profile is not unlike that found by Patel et al. (1983) in the plasma of a patient with a pancreatic somatostatinoma, but it differs in one important respect: the appearance in the plasma from our patient of a form intermediate in size between SRIF14 and SRIF-28 which contained the mid-through carboxy-terminal portion of SRIF-14. Although this form corresponded in elution position with that found by Patel et al. (1983), in their case the peptide did not contain the carboxy-terminus. It is interesting that in the somatostatinoma case cited above (Axelrod et al., 1981) with low basal levels of both insulin and glucagon, the predominant SRIF-LI form in the plasma co-migrated with SRIF-14 on gel filtration, which may explain the modest ketonaemia detected in that case. In our patient the presence of the larger molecular weight forms may have contributed to greater suppression of insulin that glucagon secretion with resultant more severe ketogenesis.

The subsequent course of our patient without dependence on insulin may have several explanations. Although the peripheral serum IRI was low, the portal insulin concentration and perhaps more importantly, the portal insulin to glucagon molar ratio (McGarry $\&$ Foster, 1980) may have been unfavourable for ketogenesis. The recovery from infection and dehydration probably significantly decreased resistance to the action of insulin. Additionally, it is possible that inhibition of gastrointestinal absorption (Schusdziarra et al., 1980) or enhancement of glucose clearance (Ader \& Bergman, 1985) by SRIF contributed to lessening of the hyperglycaemia, and hepatic gluconeogenesis may have been impaired due to hepatic replacement by metastatic tumour.

The finding of elevated serum CEA and diffuse CEA immunoreactivity of the tumour cells in this somatostatinoma case has been described in other neuroendocrine tumours, including medullary carcinoma of the thyroid (MCT) (Ishikawa \& Hamada, 1976), small cell carcinoma of the lung (Lokich, 1982) and neuroblastoma (Reynoso et al., 1972). CEA levels, if elevated, may be useful clinically for the estimation of tumour burden following chemotherapy and for calculation of tumour doubling time for prognostic purposes. Making this assumption, the increase in serum CEA from $7.5 \mu \mathrm{g} / 1$ to $44.7 \mu \mathrm{g} / 1$ over an 8 -month period in our case predicts a rapid doubling time of just over 3 months. An estimated tumour doubling time of 6-12 months in MCT has been associated with a poor prognosis (Miyauchi et al., 1984; Saad et al., 1984).

Tumour cell immunoreactivity for the granule protein chromogranin and the antigenic marker NSE has been characteristic of other neuroendocrine neoplasms (O'Connor et al., 1983; Lloyd \& Wilson, 1983; Lloyd et al., 1984; Simpson et al., 1984); one somatostatinoma with positive NSE but negative chromogranin immunoreactivity has been reported (Lloyd et al., 1984). Bombesin-LI has been a common marker of neuroendocrine cells, especially neuroepithelial bodies of the lung (Gould et al., 1983) and those tumours which express multiple hormones (Abe et al., 1984; Price et al., 1985). The finding of SRIF immunoreactivity in only $5-10 \%$ of the tumour cells in our case may be explained by rapid 
turnover and little storage of preformed hormone by the neoplastic cells.

By light microscopy alone, the tumour in this patient appeared to be a poorly differentiated adenocarcinoma. Only after clinical detection of SRIF hypersecretion were additional morphologic and immunohistochemical studies performed which allowed reclassification of the neoplasm as a non-small cell poorly differentiated neuroendocrine carcinoma. The sometimes elusive endocrine nature of such pulmonary tumours has been previously noted (McDowell et al., 1981). Evidence of simultaneous multidirectional differentiation in this tumour was provided by the presence of stainable mucin, argyrophilic granules, immunoreactivity for multiple hormones, and the ultrastructural features of desmosomes, tonofilament bundles, intracytoplasmic lumens, and neurosecretory granules. Routine ultrastructural and immunohistochemical studies have demonstrated such overlapping patterns of differentiation in $2 \%$ of bronchogenic carcinomas of all types (Yesner, 1978) and 30\% of pulmonary neuroendocrine carcinomas of all types (Gould et al., 1983). Further investigation of this type of pluripotent differentiation and delineation of the neurohormonal influences on tumour growth and development hold great promise in advancing the basic understanding of neoplasia.

\section{ACKNOWLEDGEMENTS}

We gratefully acknowledge the technical assistance of Ms Donna Harmon in performing the post-mortem examination, Ms Susan Beard and Ms Dana Hockett Evans in preparation of the manuscript, and Mr Piyush Kothary in carrying out the chromatographic analysis.

\section{REFERENCES}

Abe, K., Yamaguchi, K., Adachi, I., Suzuki, M., Kumura, S., Shimada, A., Maruno, K. \& Yanalhara, N. (1984) Production of gastrin-releasing peptide (bombesin) by tumors. In Endocrinology: Proceedings of the 7th International Congress of Endocrinology (eds F. Labrie \& L. Proulx), pp. 77-80. Excerpta Medica, Amsterdam, New York, Oxford.

AdER, M. \& BERGMAN, R.N. (1985) Direct effect of somatostatin infusion to increase glucose clearance in dogs. In Program and Abstracts of the Sixty-Seventh Annual Meeting of The Endocrine Society. Baltimore, Maryland. Abstract 102.

Axelrod, L., Bush, M.A., Hirsch, H.J. \& Loo, S.W.H. (1981) Malignant somatostatinoma: Clinical features and metabolic studies. Journal of Clinical Endocrinology and Metabolism, 52, 886-896.

Brazeau, P., Ling, N., Esch, F., Bohlen, P., Benoit, P., Benoit, R. \& Guillemin, R. (1981) High biological activity of the synthetic replicates of somatostatin-28 and somatostatin-25. Regulatory Peptides, 1,255 264.

COnlon, J.M., MCCARThy, D., KreJs, G. \& Unger, R.H. (1981) Characterization of somatostatin-like components in the tumors and plasma of a patient with somatostatinoma. Journal of Clinical Endocrinology and Metabolism, 52, 66-73.

Galmiche, J.P., Colin, R., DuBois, P.M., Chayvialle, J.A., Descos, F., Paulin, C. \& Geffroy, Y. (1978) Calcitonin secretion by a pancreatic somatostatinoma (letter). New England Journal of Medicine, $299,1252$.

Ganda, O.P., Weir, G.C., Soeldner, J.S., LegG, M.A., Chick, W.L., Patel, Y.C., Ebeid, A.M., Gabbay, K.H. \& ReICHLIN, S. (1977) Somatostatinoma: A somatostatin-containing tumor of the endocrine pancreas. New England Journal of Medicine, 296, 963-967.

Gerich, J.E., Lorenzi, M., Bier, D.M., Schneider, V., Tsalikian, E., Karam, J.H. \& Forsham, P.H. (1975a) Prevention of human diabetic ketoacidosis by somatostatin: Evidence for an essential role of glucagon. New England Journal of Medicine, 292, 985-989. 
Gerich, J.E., Lovinger, P. \& Grodsky, G.M. (1975b) Inhibition by somatostatin of glucagon and insulin release from the perfused rat pancreas in response to arginine, isoproterenol and theophylline: evidence for a preferential effect on glucagon secretion. Endocrinology, 96, 749 754.

Gerlock Jr, A.J., Muhletaler, C.A., Halter, S. \& Goncharenko, V. (1979) Pancreatic somatostatinoma: Histologic, clinical, and angiographic features. American Journal of Roentgenology, 133, 939-943.

Ghose, R.R. \& GuPTA, S.K. (1981) Oat cell carcinoma of bronchus presenting with somatostatinoma syndrome. Thorax, 36, 550-551.

Gould, V.E., Linnolla, R.I., Memoli, V.A. \& Warren, W.H. (1983) Neuroendocrine components of the bronchopulmonary tract: Hyperplasias, dysplasias, and neoplasms. Laboratory Investigation, 49, 519-537.

HsU, S.M., RAINE, L. \& FANGER, H. (1981) A comparative study of the peroxidase-antiperoxidase method and an avidin-biotin complex method for studying polypeptide hormones with radioimmunoassay antibodies. American Journal of Clinical Pathology, 75, 732-738.

IsHIKaWA, N.\& HAMADA, S. (1976) Association of medullary carcinoma of the thyroid with carcinomembryonic antigen. British Journal of Cancer, 34, 111-115.

Ito, S., Yamada, Y., IwanaGa, T., Kaneko, H. \& Shibata, A. (1982) Somatostatin-28-like immunoreactivity in normal and tumor tissue from duodenum and pancreas. Acta Endocrinologica, 101, $421-427$.

Keller, U., Chiasson, J-L., Liljenquist, J.E., Cherrington, A.D., Jennings, A.S. \& Crofford, O.B. (1977) The roles of insulin, glucagon, and free fatty acids in the regulation of ketogenesis in dogs. Diabetes, 26, 1040-1051.

KELLY, T.R. (1983) Pancreatic somatostatinoma. American Journal of Surgery, 146, 671-673.

Kothary, P.C., Vinik, A.I., Owyang, C. \& Fiddian-Green, R.G. (1983) Immunochemical studies of molecular heterogeneity of cholecystokinin in duodenal perfusates and plasma in humans. Journal of Biological Chemistry, 258, 2856-2863.

Krejs, G.J., Orci, L., Conlon, J.M., Ravazzola, M., Davis, G.R., Raskin, P., Collins, S.M., McCarthy, D.M., Baftens, D., Rubenstein, A., Aldor, T.A.M.\& Unger, R.H. (1979) Somatostatinoma syndrome: Biochemical, morphologic and clinical features. New England Journal of Medicine, 301, 285-292.

Larsson, L-I., Hirsch, M.A., Holst, J.J., Ingemansson, S., Kuhl, C., Lindkaer Jensen, S., Lundquist, G., ReHFELD, J.F. \& Schwartz, T.W. (1977) Pancreatic somatostatinoma: Clinical features and physiological implications. Lancet, i, 666-668.

LLOYD, R.V.\& WILSON, B.S. (1983) Specific endocrine tissue marker defined by a monoclonal antibody. Science, 222, 628-630.

Lloyd, R.V., Mervak, T., Warner, T.F.C.S., Schmidt, K. \& Wilson, B.S. (1984) Immunohistochemical detection of chromogranin and neuron-specific enolase in pancreatic endocrine neoplasms. American Journal of Surgical Pathology, 8, 607-614.

LOKICH, J.J. (1982) Plasma CEA levels in small cell lung cancer: Correlation with stage, distribution of metastases, and survival. Cancer, 50, 2154-2156.

Mandarino, L., Stenner, D., Blanchard, W., Nissen, S., Gerich, J., Ling, N., Brazeau, P., Bohlen, P., Esch, F. \& Guillemin, R. (1981) Selective effects of somatostatin-14, -25 and -28 on in vitro insulin and glucagon secretion. Nature, 291, 76-77.

McDowell, E.M., Wilson, T.S. \& Trump, B.F. (1981) Atypical endocrine tumors of the lung. Archives of Pathology and Laboratory Medicine, 105, 20-28.

MCGARRY, J.D. \& FOSTER, D.W. (1980) Regulation of hepatic fatty acid oxidation and ketone body production. Annual Review of Biochemistry, 49, 395-420.

Miyauchi, A., Onishi, T., Morimoto, S., Shin-Ichiro, T., Matsuzuka, F., Kuma, K., Masazumi, M. \& Kumahara, Y. (1984) Relation of doubling time of plasma calcitonin level to prognosis and recurrence of medullary thyroid carcinoma. Annals of Surgery, 199, 461-466.

Nakanome, C., Kolzumi, M., Funya, H., Akai, H., Toyota, T., Goto, Y., Kameyama, J., Miyakawa, K. \& HANEW, K. (1984) Somatostatinoma syndrome accompanied by overproduction of pancreatic polypeptide. Tohoku Journal of Experimental Medicine, 142, 201-210.

O'Connor, D.T., Burton, D. \& Deftos, L..J. (1983) Immunoreactive human chromogranin A in diverse polypeptide hormone producing human tumors and normal endocrine tissues. Journal of Clinical Endocrinology and Metabolism, 57, 1084-1086.

Patel, Y.C., Ganda, O.M. \& Benolt, R. (1983) Pancreatic somatostatinoma: Abundance of somatostatin-28 $8_{(1-12)}$-like immunoreactivity in tumor and plasma. Journal of Clinical Endocrinology and Metabolism, 57, 1048-1053.

Penman, E., Lowry, P.J., Wass, J.A.H., Marks, V., Dawson, A.M., Besser, G.M. \& Rees, L.H. (1980) 
Molecular forms of somatostatin in normal subjects and in patients with pancreatic somatostatinoma. Clinical Endocrinology, 12, 611-620.

Pipeleers, D., Somers, G., Gepts, W., De Nutte, N. \& De Vroede, M. (1979) Plasma pancreatic hormone levels in a case of somatostatinoma: Diagnostic and therapeutic implications. Journal of Clinical Endocrinology and Metabolism, 49, 572-579.

Price, J., Nieuwenhuijzen Kruseman, A.C., Doniach, I., Howlett, T.A., Besser, G.M. \& Rees, L.H. (1985) Bombesin-like peptides in human endocrine tumors: Quantitation, biochemical characterization, and secretion. Journal of Clinical Endocrinology and Metabolism, 60, 1097-1103.

Reynoso, G., Chu, T.M., Holyoke, D., Cohen, E., Nemoto, T., Wang, J.J., Chuang, J., Guinan, P. \& MurPhy, G.P. (1972) Carcinoembryonic antigen in patients with different cancers. Journal of the American Medical Association, 220, 361-365.

SAAD, M.F., Fritsche JR, H.A. \& SAMAAN, N.A. (1984) Diagnostic and prognostic values of carcinoembryonic antigen in medullary carcinoma of the thyroid. Journal of Clinical Endocrinology and Metabolism, 58, 889 894.

Schusdziarra, V., Zyznar, E., Roulller, D., Boden, G., Brown, J.C., Arimura, A. \& Unger, R.H. (1980) Splanchnic somatostatin: A hormonal regulator of nutrient homeostasis. Science, 207, 530-532.

Schusdziarra, V. Grube, D., Seifert, H., Galle, J., Etzrodt, H., Beischer, W., Haferkamp, O. \& Pfeiffer, E.F. (1983) Somatostatinoma syndrome: Clinical, morphological and metabolic features and therapeutic aspects. Klinische Wochenschrift, 61, 681-689.

Simpson, S., Vinik, A.I., Marangos, P.J. \& Lloyd, R.V. (1984) Immunohistochemical localization of neuronspecific enolase in gastroentero-pancreatic neuroendocrine tumors. Correlation with tissue and serum levels of neuron-specific enolase. Cancer, 54, 1364-1369.

Sive, A.A., VINIK, A.I. \& LeviTt, N.S. (1980) Adrenergic modulation of human pancreatic polypeptide (hPP) release. Gastroenterology, 79, 665-672.

StaRr, J.I. \& RubensteIN, A.H. (1974) Insulin, proinsulin and C-peptide. In Methods of Hormone Radioimmunoassay (eds B. M. Jaffe \& H. R. Behrman), pp. 289-315. Academic Press, New York.

Strodel, W.E., Vinik, A.I., Joffe, B.M., Eckhauser, F.E. \& Thompson, N.W. (1984) Substance P in localization of carcinoid tumors. Journal of Surgical Oncology, 27, 106-111.

Susini, C., Esteve, J.P., Vaysse, N., Pradayrol, L. \& Ribet, A. (1980) Somatostatin-28: Effects on exocrine pancreatic secretion in conscious dogs. Gastroenterology, 79, 720-724.

TANNENBAUM, G.S., LING, N. \& BRAZEAU, P. (1982) Somatostatin-28 is longer acting and more selective than somatostatin- 14 on pituitary and pancreatic hormone release. Endocrinology, 111, 101-107.

TASHJian JR, A.H. (1969) Immunoassay of calcitonin. 1. The method and its serological specificity. Endocrinology, 84, 140-148.

Tran, V.T., Beal, M.F. \& Martin, J.B. (1985) Two types of somatostatin receptors differentiated by cyclic somatostatin analogs. Science, 228, 492-495.

UNGER, R.H. (1977) Editorial. Somatostatinoma. New England Journal of Medicine, 296, 998-1000.

VINIK, A.I., LevitT, N.S., Pimstone, B.L. \& WAGner, L. (1981a) Peripheral plasma somatostatin-like immunoreactive responses to insulin hypoglycemia and a mixed meal in healthy subjects and in noninsulindependent maturity-onset diabetics. Journal of Clinical Endocrinology and Metabolism, 52, 330-337.

Vinik, A.I., Gaginella, T.S., O'Dorisio, T.M., Shapiro, B. \& Wagner, L. (1981b) The distribution and characterization of somatostatin-like immunoreactivity in epithelial cells, submucosa, and muscle of the rat stomach and intestine. Endocrinology, 109, 1921-1926.

VINIK, A.I., STrodel, W.E. \& O'Dorisio, T.M. (1984) Endocrine tumors of the gastroenteropancreatic axis. In Diagnosis and Management of Endocrine-related tumors (eds R. J. Santen \& A. Manni), pp. 235-304. Martinus Nijhoff, Boston.

YeSNER, R. (1978) Spectrum of lung cancers and ectopic hormones. In Pathology Annual 13 (part 1) (eds S. C. Sommers \& P. P. Rosen), pp. 217-240. Appleton-Century-Crofts, New York. 